\title{
Reactive Power Control for Distributed Generation Power Plants to Comply with Voltage Limits During Grid Faults
}

\author{
Antonio Camacho, Miguel Castilla, Jaume Miret, Member, IEEE, Ramon Guzman and Angel Borrell
}

\begin{abstract}
Grid faults are one of the most severe problems for network operation. Distributed generation power plants can help to mitigate the adverse effects of these perturbations by injecting reactive power during the sag and the post-fault operation. Thus, the risk of cascade disconnection and voltage collapse can be reduced. The proposed reactive power control is intended to regulate the maximum and minimum phase voltages at the point of common coupling within the limits established in grid codes for continuous operation. In balanced three-phase voltage sags, the control increases the voltage in each phase above the lower regulated limit by injecting positive sequence reactive power. In unbalanced voltage sags, positive and negative sequence reactive powers are combined to flexibly raise and equalize the phase voltages; maximum phase voltage is regulated below the upper limit and the minimum phase voltage just above the lower limit. The proposed control strategy is tested by considering a distant grid fault and a large grid impedance. Selected experimental results are reported in order to validate the behavior of the control scheme.
\end{abstract}

Index Terms-Reactive power control, grid fault, voltage sag, voltage support, positive and negative sequence control.

\section{INTRODUCTION}

$\mathbf{T}$ HE high penetration level of renewable energy sources and distributed generation (DG) plants faces new challenges in the operation of transmission and distribution networks [1]-[3]. The growing installed power from DG plants has led to a change in the requirements for ancillary services, particularly during grid faults. Among these new services, voltage control in wind plants, photovoltaic parks and other large-scale power plants is gaining increasing attention due to its capability to improve grid efficiency, safety and reliability in a distributed manner.

A voltage sag is a perturbation in the grid voltages characterized by a short-time reduction in the magnitude of one or several phases. The effects of such disturbances are important in terms of economic losses, malfunction of devices connected to the grid and in extreme cases, black-outs [4]. To

This work was supported by the Spanish Ministry of Economy and Competitiveness under Grant ENE2012-37667-C02-02.

A. Camacho, M. Castilla and J. Miret are with the Department of Electronic Engineering, Technical University of Catalonia, 08800 Vilanova i la Geltrú, Spain (e-mail: antonio.camacho.santiago@upc.edu; miquel.castilla@upc.edu; jmiret@eel.upc.edu)

R. Guzman is with the Department of Signal Theory and Communications, Technical University of Catalonia, 08800 Vilanova i la Geltrú, Spain (e-mail guzman@tsc.upc.edu)

A. Borrell is with the Department of Electrical Engineering, Escola Universitària Salesiana de Sarrià, Autonomous University of Barcelona, 08017 Barcelona, Spain (e-mail: aborrell@euss.es) alleviate the adverse effects of grid faults, grid codes from the network system operators dictate the behaviour of DG plants. The evolution of these codes for DG during grid faults started with low-voltage ride-through, which demands withstanding voltage sags. As the penetration level of DG sources was increased, reactive power injection was included in grid codes to support the grid voltage and to reduce the possibility of voltage collapse [5]. The next generation of grid codes could require negative sequence current injection [6] and voltage support control [7]-[9] in steady-state and transient. The aim is to regulate the point of common coupling (PCC) voltage to a safety range, preventing damage in the equipment while improving voltage support services.

In a real distribution power system, the capacity of voltage restoration is obviously limited by the power rating and the grid stiffness. Grid codes are demanding more reactive power capacity to improve the contingency against faults [8], [10]. The use of these extra resources can be adapted to implement smart voltage support services during distant grid faults. A smart voltage support service, as proposed below, should regulate the phase voltages within the limits established in grid codes for continuous operation [11]. The safety limit strategy depends on particular grid codes, and each code provides its own specification for continuous operation, although most of them state the maximum voltage limit at 1.10 per unit (p.u.), and the minimum at 0.85 p.u. In type I voltage sags (one dropped phase) or type II (two dropped phases), the reactive power strategy should be different than the strategy for type III (three dropped phases) sags [12]. Balanced type III sags only require positive sequence reactive power to raise the phase voltages above the lower limit, since this type of grid fault lacks negative sequence voltage. On the other hand, unbalanced type I and II sags require a flexible combination of positive and negative sequence reactive power to avoid undervoltage in the faulted phase(s) and over-voltage in the nonfaulted phase(s) [13].

Advanced control algorithms to ride through different types of voltage sags are mainly based on symmetric sequences [13]-[29]. Some of these studies have been proposed to achieve particular control objectives related to power oscillations, total harmonic distortion, power factor, dclink ripple, or peak current limitation during balanced and unbalanced grid faults [16]-[23]. However, little work has been developed for voltage support control during unbalanced voltage sags [24]-[29], and they are based on voltage sequence amplitudes as voltage targets. Hence, to further improve 


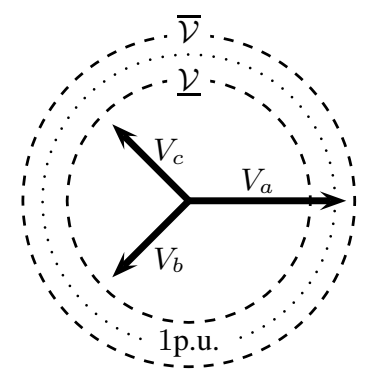

(a) PCC phase voltages without reactive power $\left(Q^{+}=0, Q^{-}=0\right)$

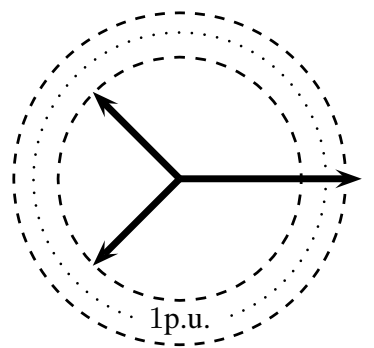

(b) Positive sequence reactive power strategy $\left(Q^{+}>0, Q^{-}=0\right)$
Fig. 1. Phase voltages for different reactive power strategies.

voltage support services, phase voltage regulation instead of voltage sequence regulation is developed in this work, since this is the main concern to remain connected in some grid codes during grid faults [30].

In contrast, the reactive power control proposed in this work tries to solve the aforementioned problem and extends the contribution of [31] for any type of voltage sag. In [31], only symmetric sags were considered. However, voltage sags are very complex phenomena [4], [12], [32]. As shown in that works, some of the recorded sags are asymmetric and timevarying. To achieve all these features, a detailed mathematical formulation is developed to set the voltage targets, and a simplified impedance model is used to compute the reactive power references.

The paper is organized as follows. Section II formulates the problem. Section III introduces the DG plant and the control scheme during grid faults. Section IV develops the voltage support concept. Section V focuses on the proposed solution. Section VI presents a saturation technique to protect against inverter overcurrent. Section VII shows the experimental results. Finally, section VIII presents the conclusions.

\section{Problem Formulation}

This study is intended to support the grid voltage in medium or high rated DG power plants, as for example wind farms or photovoltaic parks, which are interfaced to the grid by means of power electronic converters. These plants are subject to very stringent requirements during grid faults depending on the rated power, and the grid operators require huge amounts of reactive power, both steady-state and dynamic to support the grid voltage [8]. Typically the most stringent requirements in grid codes apply for power plants rated above 30MW [33].

Whenever a sag occurs close to a DG power plant, the circuit breakers isolate the system to prevent damage. However, if the sag occurs far away, low-voltage ride-through is mandatory, and grid codes demand reactive current injection to avoid cascade disconnection and reduce the risk of blackout. For distant grid faults, if the grid impedance and the plant rated current are large enough, then the voltage can be supported by an appropriate reactive power strategy. As stated previously, the main objective in voltage support control is the avoidance of over-voltage and under-voltage at the PCC whenever possible.

Throughout this paper, the safety voltage limits for

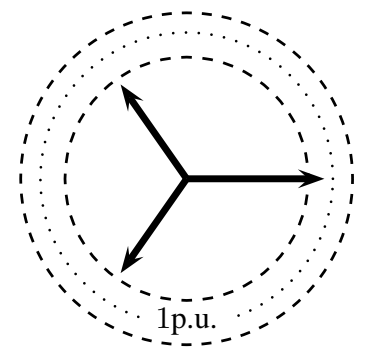

(c) Negative sequence reactive power strategy $\left(Q^{+}=0, Q^{-}>0\right)$

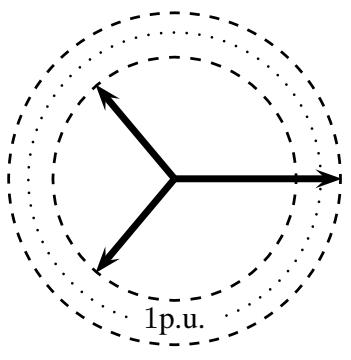

(d) Proposed reactive power strategy $\left(Q^{+}>0, Q^{-}>0\right)$ continuous operation are defined as

$$
\begin{aligned}
& \overline{\mathcal{V}}:=1.10 \text { p.u. } \\
& \underline{\mathcal{V}}:=0.85 \text { p.u. }
\end{aligned}
$$

where $\overline{\mathcal{V}}$ is the upper safety limit and $\underline{\mathcal{V}}$ is the lower one, which correspond to the most stringent limits provided in some grid codes to remain connected during grid faults [6]. However, these limits depend on national grid codes and can take different values for different regulations [11]. These voltage thresholds define the safety region in which the three-phase voltage amplitudes must reside regardless of the fault type. Beyond these limits, the system should disconnect because of over-voltage or under-voltage, according to the functionalities of the power equipment and the trip times established in grid codes [11]. The trip times are needed to avoid unnecessary disconnection by short time transient voltages.

To meet these limits, a combination of positive $Q^{+}$and negative $Q^{-}$sequence reactive power [34] can be injected into an inductive grid to support the grid voltage. Positive sequence reactive power is related to the amplitude of the current $90^{\circ}$ leading from the positive sequence voltage (i.e. the reactive current injected via positive sequence). The same applies for negative sequence reactive power, although it is shifted from the negative sequence voltage.

To understand the proposed reactive power control, Fig. 1 presents different strategies of reactive power injection [13] during a voltage sag. The figure shows the three-phase voltages $V_{a}, V_{b}$ and $V_{c}$. The dashed line highlights the safety limits $\overline{\mathcal{V}}$ and $\underline{\mathcal{V}}$. The dotted line indicates the nominal voltage. The figure is divided in four parts. On the left, Fig. 1(a), the phase voltages at the PCC without voltage support are shown. If the reactive power is injected via positive sequence $Q^{+}>0$, $Q^{-}=0$, then the voltage in each phase raises equally as shown in Fig. 1(b). The phase voltages should raise until the minimum phase voltage achieves the lowest voltage limit to comply with grid codes. The problem with this strategy is that the highest phase voltage $V_{a}$ suffers over-voltage. However, when the reactive power is injected via negative sequence $Q^{+}=0, Q^{-}>0$, the phase voltages tend to be equalized as presented in Fig. 1(c). The problem is that two phase voltages, $V_{b}$ and $V_{c}$, suffer under-voltage. From these two figures, it can be concluded that some flexible combination of both positive and negative sequence reactive power can regulate the maximum phase voltage to the safety upper limit $\overline{\mathcal{V}}$ and the minimum phase voltage to the lower one $\underline{\mathcal{V}}$. This 
strategy is adopted in this work and can be clearly understood from Fig. 1(d).

It is worth mentioning that there exist more stringent targets, such as the maximization and minimization of the voltage sequences or the regulation of the three phase voltages at the nominal pre-fault values (i.e. $V_{a}=V_{b}=V_{c} \approx 1$ p.u.). However, these strategies require higher currents.

A particular case can occur for low unbalanced sags, i.e. when the difference between the maximum and minimum phase voltages is less than the difference between upper and lower safety limits. In this case, negative sequence voltage is either zero or quite low. In this situation, the best strategy in terms of reducing the injected current, is to only supply positive sequence reactive power. Then, the three-phase voltages will raise equally until the lowest one achieves the lower safety limit.

The problem in complying with voltage limits during grid faults can be formulated as:

$$
\begin{aligned}
\text { find } & Q^{+}, Q^{-} \\
\text {such that: } & \max \left\{V_{a}, V_{b}, V_{c}\right\} \leq \overline{\mathcal{V}} \\
& \min \left\{V_{a}, V_{b}, V_{c}\right\} \geq \underline{\mathcal{V}} .
\end{aligned}
$$

The solution to the problem consists in finding which are the values for the positive and negative sequence reactive power references, $Q^{+}, Q^{-}$, such that the maximum amplitude of the phase voltages $V_{a}, V_{b}, V_{c}$ is kept below the safety upper limit $\overline{\mathcal{V}}$, and the minimum above the lower voltage limit $\underline{\mathcal{V}}$.

Some assumptions are needed in order to simplify the theoretical study:

- the grid impedance is mainly inductive,

- the grid impedance is approximately known,

- only reactive power is injected during the fault.

The first assumption holds in transmission and distribution networks with high $X / R$ ratio. The second assumption indicates that the grid impedance can be estimated even if it changes. To do so, a well known grid model or a proper grid impedance estimator [35]-[39] is required. The third assumption is required in some grid codes for deep voltage sags because the reactive power capacity can be strongly increased. In shallow voltage sags, active and reactive power should be simultaneously injected to support and feed the grid. However, for the sake of clear demonstration, in this work active power is set to zero during the sag.

\section{DG POWER Plant Under GRID FAUlts}

This section develops three basic aspects to control DG power plants during grid faults. First, the basic architecture of the plant is presented. Second, the voltage sag is analyzed based on symmetric sequences. Finally, the control scheme is assessed.

\section{A. DG Power Plant Architecture}

DG power plants are considered a key element to improve the grid operation. Wind farms and photovoltaic parks are the most widely extended example of DG plants with flexible operation during grid faults. These medium to high rated

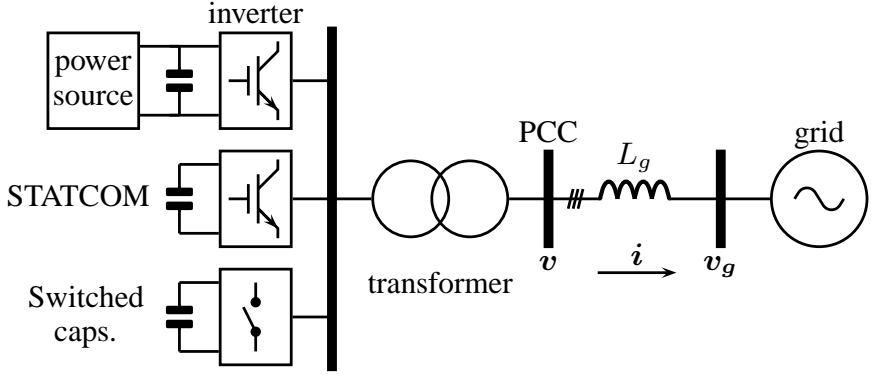

Fig. 2. Simplified scheme of a DG power plant.

power facilities are made up of the following VAr devices [7]

- power inverters

- STATCOMs

- switched capacitors

Power inverters can be controlled to supply both active and reactive power. Moreover, full-scale power converters are becoming the preferred choice in wind turbine technology because of their flexibility [40]. STATCOMs provide some dynamic reactive power required by grid codes. Steady-state VAr compensation is mainly operated by switched capacitors since they present lower investment cost. All these elements allow the power plant to behave as an equivalent power system that exchanges active and reactive power at the PCC [10]. For proper operation, a communication infrastructure with networked control schemes is shared among the elements of the plant; the dependency among the inner elements of the power plant ( $P$ and $Q$ dispatchers) are out of the scope of this work. For an in deep analysis of fault operation modes, see [7]. Under this consideration, Fig. 2 shows a simplified configuration of a grid-connected DG power plant which behaves as an active and reactive power source from a system operator point of view.

The complete system is composed of power sources, dclink capacitors, inverters, filters, and step-up transformer. The plant is connected to the grid at the PCC. The inductance $L_{g}$ is used to model the grid impedance. The grid voltage $\boldsymbol{v}_{\boldsymbol{g}}$ represents the fault produced somewhere in the transmission or distribution network.

\section{B. Voltage Sag Identification}

For a proper control under grid fault, the voltage $v$ at the PCC is of interest. The instantaneous phase voltages need to be processed in order to identify the characteristics of the voltage sag based on symmetric sequences. Using Clarke transformation in a three-wire system, the instantaneous voltages can be expressed in the stationary reference frame (SRF) as

$$
\left[\begin{array}{l}
v_{\alpha} \\
v_{\beta}
\end{array}\right]=\frac{1}{3}\left[\begin{array}{ccc}
2 & -1 & -1 \\
0 & \sqrt{3} & -\sqrt{3}
\end{array}\right]\left[\begin{array}{l}
v_{a} \\
v_{b} \\
v_{c}
\end{array}\right]
$$

The SRF voltages can be separated into positive and 


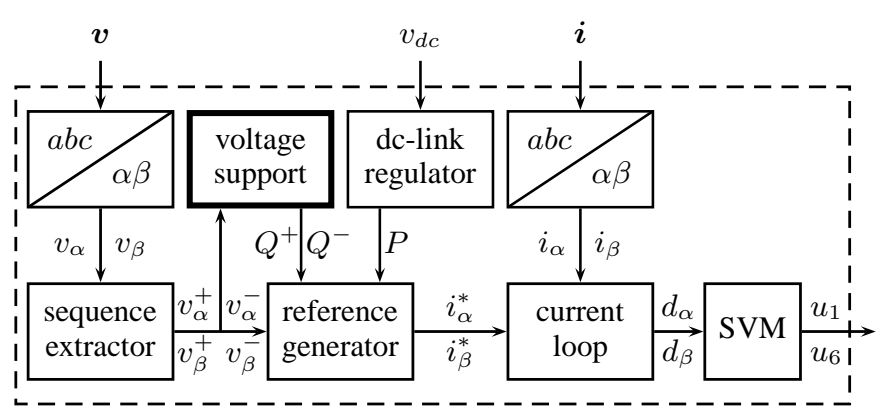

Fig. 3. Control diagram of a three-phase inverter.

negative sequence as

$$
\begin{aligned}
& v_{\alpha}=v_{\alpha}^{+}+v_{\alpha}^{-} \\
& v_{\beta}=v_{\beta}^{+}+v_{\beta}^{-}
\end{aligned}
$$

where $v_{\alpha}^{+}$and $v_{\beta}^{+}$are the instantaneous positive sequence voltage in the SRF and $v_{\alpha}^{-}$and $v_{\beta}^{-}$are the negative ones.

Positive and negative sequence voltages as a function of time can be represented as

$$
\begin{aligned}
& v_{\alpha}^{+}=V^{+} \cos \left(\omega t+\varphi^{+}\right) \\
& v_{\beta}^{+}=V^{+} \cos \left(\omega t-\frac{\pi}{2}+\varphi^{+}\right) \\
& v_{\alpha}^{-}=V^{-} \cos \left(\omega t-\varphi^{-}\right) \\
& v_{\beta}^{-}=V^{-} \cos \left(\omega t+\frac{\pi}{2}-\varphi^{-}\right)
\end{aligned}
$$

where $V^{+}, V^{-}$are the amplitudes of the positive and negative sequences respectively, $\omega$ is the grid frequency and $\varphi^{+}, \varphi^{-}$ are the initial phase angles of positive and negative sequences.

From (7)-(10), the amplitudes $V^{+}$and $V^{-}$are obtained as

$$
\begin{aligned}
& V^{+}=\sqrt{\left(v_{\alpha}^{+}\right)^{2}+\left(v_{\beta}^{+}\right)^{2}} \\
& V^{-}=\sqrt{\left(v_{\alpha}^{-}\right)^{2}+\left(v_{\beta}^{-}\right)^{2}}
\end{aligned}
$$

and the angle $\varphi=\varphi^{+}-\varphi^{-}$between the positive and negative sequence is obtained from

$$
\begin{aligned}
\cos (\varphi) & =\frac{v_{\alpha}^{+} v_{\alpha}^{-}-v_{\beta}^{+} v_{\beta}^{-}}{V^{+} V^{-}} \\
\sin (\varphi) & =\frac{v_{\alpha}^{+} v_{\beta}^{-}+v_{\beta}^{+} v_{\alpha}^{-}}{V^{+} V^{-}} .
\end{aligned}
$$

\section{Control Scheme}

The behavior of the power plant is determined by the injected current at the PCC. Thus, a proper current-mode control, capable of riding through voltage sags is required. Fig. 3 shows a control block diagram for voltage support during grid faults. The inputs of the controller are local measured voltages $\boldsymbol{v}$ and currents $\boldsymbol{i}$ and the dc-link voltage $v_{d c}$. Voltages $\boldsymbol{v}$ and currents $\boldsymbol{i}$ are transformed into SRF values. Voltages $v_{\alpha}$ and $v_{\beta}$ are split into their symmetric components $v_{\alpha}^{+}$, $v_{\beta}^{+}, v_{\alpha}^{-}$and $v_{\beta}^{-}$by using a sequence extractor [41]-[46]. The voltage support block detects the voltage sag and provides the reactive power references $Q^{+}$and $Q^{-}$to the reference generator. The dc-link voltage regulator controls the active power reference $P$, which is set to zero during the sag as assumed previously. Energy storage elements, active crowbars among other fast active control schemes are required to keep active power balance during short-time grid faults and prevent damage in the equipment. These last two blocks constitute the power loop, since they provide the active and reactive power references. All this information passes through the reference generator to build the reference currents $i_{\alpha}^{*}$ and $i_{\beta}^{*}$, which allow the injection of reactive power via positive and negative sequences. The current reference generator is implemented as [13]

$$
\begin{aligned}
& i_{\alpha}^{*}=\frac{2}{3}\left[\frac{v_{\beta}^{+}}{\left(v_{\alpha}^{+}\right)^{2}+\left(v_{\beta}^{+}\right)^{2}} Q^{+}+\frac{v_{\beta}^{-}}{\left(v_{\alpha}^{-}\right)^{2}+\left(v_{\beta}^{-}\right)^{2}} Q^{-}\right] \\
& i_{\beta}^{*}=\frac{-2}{3}\left[\frac{v_{\alpha}^{+}}{\left(v_{\alpha}^{+}\right)^{2}+\left(v_{\beta}^{+}\right)^{2}} Q^{+}+\frac{v_{\alpha}^{-}}{\left(v_{\alpha}^{-}\right)^{2}+\left(v_{\beta}^{-}\right)^{2}} Q^{-}\right]
\end{aligned}
$$

where each channel has a positive and a negative sequence term.

The last stages in Fig. 3 correspond to the current loop, where the references are compared with the measured currents. The current control loop provides the duty cycles $d_{\alpha}$ and $d_{\beta}$ that are processed by the space vector pulse width modulator (SVM) to drive the switches $u_{1}, u_{2}, \ldots u_{6}$.

\section{Voltage Support CONCEPT}

Inside the voltage support block in Fig. 3, the mathematical computation of the reactive power references is obtained. These references are computed on-line so as to achieve the objective in (3). The voltage support service at the PCC (see Fig. 2) can be expressed as a function of the grid voltage and the injected current as

$$
\begin{aligned}
& v_{\alpha}=v_{g \alpha}+L_{g} \frac{\mathrm{d} i_{\alpha}}{\mathrm{d} t} \\
& v_{\beta}=v_{g \beta}+L_{g} \frac{\mathrm{d} i_{\beta}}{\mathrm{d} t}
\end{aligned}
$$

where $v_{g \alpha}$ and $v_{g \beta}$ are the grid voltages in the SRF, and $v_{\alpha}$, $v_{\beta}$ represent the local measures at the PCC. The magnitude of the voltage sag is derived by inserting (5)-(10), (15) and (16) in (17) and (18)

$$
\begin{gathered}
V_{g}^{+}=V^{+}-\omega L_{g} I^{+} \\
V_{g}^{-}=V^{-}+\omega L_{g} I^{-}
\end{gathered}
$$

where

$$
\begin{aligned}
I^{+} & =\frac{2}{3} \frac{Q^{+}}{V^{+}} \\
I^{-} & =\frac{2}{3} \frac{Q^{-}}{V^{-}} .
\end{aligned}
$$

From (19)-(22), it can be shown that the magnitude of the sag $V_{g}^{+}, V_{g}^{-}$can be estimated based on measured PCC voltages $V^{+}, V^{-}$and injected power $Q^{+}, Q^{-}$. Also, the voltage support concept can be explicitly described from (19)-(22). By injecting positive sequence reactive power, the positive sequence voltage at the PCC raises with respect to that of the grid. Furthermore, by injecting negative sequence reactive 


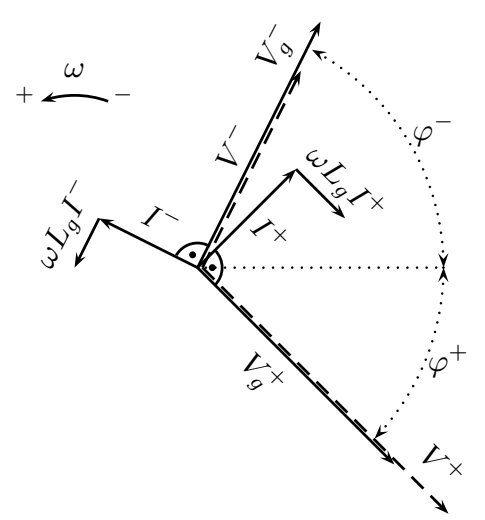

Fig. 4. Phasor representation of the reactive power control.

power, the negative sequence voltage is lower in the PCC than in the grid.

The voltage support concept can be graphically explained as in Fig.4. The grid voltage is characterized by the amplitude of the positive $V_{g}^{+}$and negative sequence voltages $V_{g}^{-}$. According to the symmetric sequences theory, the two phasors rotate in opposite directions. Then, $V_{g}^{+}$represents the positive sequence grid voltage phasor rotating counter-clockwise at $\omega$ $\mathrm{rad} / \mathrm{s}$. The initial phase angle is $\varphi^{+}$. Similarly, the negative sequence grid voltage $V_{g}^{-}$rotates clockwise. In this case, the initial angle is $\varphi^{-}$. In nominal grid conditions, the amplitude of $V_{g}^{+} \approx 1$ p.u. and $V_{g}^{-} \approx 0$ p.u. However, during the sag these phasors experience sudden changes in amplitude and phase jump. The objective of the voltage support is to increase the amplitude of the positive sequence voltage $\mathrm{V}^{+}$ at the PCC compared with the grid sequence voltage $V_{g}^{+}$; and to reduce the negative sequence voltage $V^{-}$compared with the grid one $V_{g}^{-}$. If this is accomplished, then the phase voltages are increased and the voltage imbalance reduced. Reactive current injection is the key for this voltage support objective. To inject positive sequence reactive power $Q^{+}$, a $90^{\circ}$ current leading from the positive sequence voltage is needed as obtained from the definition in (15) and (16). On the other hand, to inject negative sequence reactive power $Q^{-}$, a $90^{\circ}$ current shifted from the negative sequence voltage must be injected. When the positive and negative reactive power flow through an inductor, it produces a voltage variation which is proportional to $\omega L_{g}$. In the case of positive sequence reactive power, the voltage difference is positive, as a result the positive sequence voltage at the PCC increases by $\omega L_{g} I^{+}$volts. In the case of the negative sequence reactive power, the voltage drops by $\omega L_{g} I^{-}$, which helps to reduce the imbalance at the PCC. By flexibly combining the amounts of positive and negative reactive power, the desired voltage support strategy at the PCC can be reached, thus regulating the phase voltages according to $(3)$.

\section{Proposed Solution}

This section develops the mathematical procedure to solve the problem stated in (3). To begin with, the amplitude of phase voltages is obtained from the sag identification. Then, the relationship between the phase voltages and voltage sequences is analyzed for any type of voltage sag. Finally, the reactive power references are derived based on the grid voltage estimation.

\section{A. Amplitude of the Phase Voltages}

By applying the inverse Clarke transformation to (7)-(10), the amplitude of the phase voltages can be expressed as a function of the positive and negative sequence amplitudes and the phase angle jump between them as

$$
\begin{aligned}
& V_{a}=\sqrt{\left(V^{+}\right)^{2}+\left(V^{-}\right)^{2}+2 V^{+} V^{-} \cos (\varphi)} \\
& V_{b}=\sqrt{\left(V^{+}\right)^{2}+\left(V^{-}\right)^{2}+2 V^{+} V^{-} \cos (\varphi-2 \pi / 3)} \\
& V_{c}=\sqrt{\left(V^{+}\right)^{2}+\left(V^{-}\right)^{2}+2 V^{+} V^{-} \cos (\varphi+2 \pi / 3)} .
\end{aligned}
$$

The expressions (23)-(25) link positive and negative sequence voltages with the phase amplitudes for a given voltage sag angle. In fact, only two of the three expressions are of interest: $\max \left\{V_{a}, V_{b}, V_{c}\right\}$ and $\min \left\{V_{a}, V_{b}, V_{c}\right\}$. By defining

$$
\begin{aligned}
& x=\max \{\cos (\varphi), \cos (\varphi-2 \pi / 3), \cos (\varphi+2 \pi / 3)\} \\
& y=\min \{\cos (\varphi), \cos (\varphi-2 \pi / 3), \cos (\varphi+2 \pi / 3)\}
\end{aligned}
$$

then

$$
\begin{aligned}
\max \left\{V_{a}, V_{b}, V_{c}\right\} & =\sqrt{\left(V^{+}\right)^{2}+\left(V^{-}\right)^{2}+2 V^{+} V^{-} x} \\
\min \left\{V_{a}, V_{b}, V_{c}\right\} & =\sqrt{\left(V^{+}\right)^{2}+\left(V^{-}\right)^{2}+2 V^{+} V^{-} y}
\end{aligned}
$$

The above expressions can be used to regulate the phase amplitudes to the desired values. Henceforth, these voltage targets will be denoted with a super-index "*" in order to differentiate them from the measured values

$$
\max \left\{V_{a}^{*}, V_{b}^{*}, V_{c}^{*}\right\}=\sqrt{\left[\left(V^{+}\right)^{*}\right]^{2}+\left[\left(V^{-}\right)^{*}\right]^{2}+2\left(V^{+}\right) *\left(V^{-}\right) * x}
$$

$$
\min \left\{V_{a}^{*}, V_{b}^{*}, V_{c}^{*}\right\}=\sqrt{\left[\left(V^{+}\right)^{*}\right]^{2}+\left[\left(V^{-}\right)^{*}\right]^{2}+2\left(V^{+}\right)^{*}\left(V^{-}\right)^{*} y} .
$$

This means that if the injection of reactive power can help the measured positive or negative sequence voltages $V^{+}, V^{-}$to achieve the desired objectives $\left(V^{+}\right)^{*},\left(V^{-}\right)^{*}$, then the phase voltages $V_{a}, V_{b}$ and $V_{c}$ will be regulated to the desired values $V_{a}^{*}, V_{b}^{*}, V_{c}^{*}$. Normally voltage sags exhibit asymmetrical and time-varying profiles. Thus, in a real scenario, the max and min expressions derived in (30) and (31) are also time-varying functions.

\section{B. Targets for Positive and Negative Sequence Voltage}

As previously stated in section II, the goal is to keep phase voltages within the limits established in grid codes. Therefore, an appropriate phase voltage target should be

$$
\begin{aligned}
\max \left\{V_{a}^{*}, V_{b}^{*}, V_{c}^{*}\right\} & =\overline{\mathcal{V}} \\
\min \left\{V_{a}^{*}, V_{b}^{*}, V_{c}^{*}\right\} & =\underline{\mathcal{V}} .
\end{aligned}
$$

Replacing the phase voltages in (30) and (31) with the desired objectives (32) and (33), and solving the voltage 


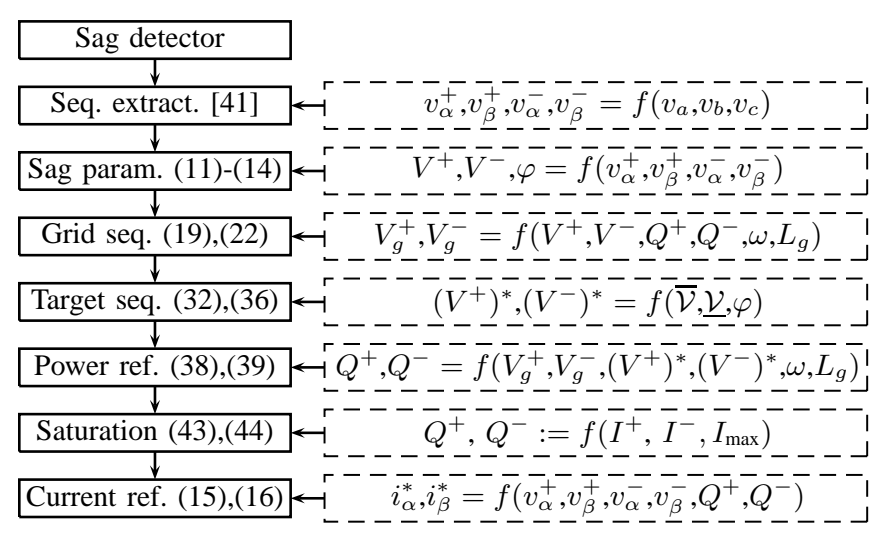

Fig. 5. Flow diagram of the proposed control scheme.

sequence targets, the following expressions are obtained

$$
\left(V^{+}\right)^{*}=\sqrt{\frac{x \underline{\mathcal{V}}^{2}-y \overline{\mathcal{V}}^{2}+\sqrt{\left(y \overline{\mathcal{V}}^{2}-x \underline{\mathcal{V}}^{2}\right)^{2}-\left(\overline{\mathcal{V}}^{2}-\underline{\mathcal{V}}^{2}\right)^{2}}}{2(x-y)}}
$$

$$
\left(V^{-}\right)^{*}=\sqrt{\frac{x \underline{\mathcal{V}}^{2}-y \overline{\mathcal{V}}^{2}-\sqrt{\left(y \overline{\mathcal{V}}^{2}-x \underline{\mathcal{V}}^{2}\right)^{2}-\left(\overline{\mathcal{V}}^{2}-\underline{\mathcal{V}}^{2}\right)^{2}}}{2(x-y)}} .
$$

Equations (34) and (35) are the basis for the proposed voltage support control because they relate phase voltage targets to sequence voltage targets. Furthermore, the above equations allow us to obtain the targets for any sag, whether symmetric or asymmetric.

For the particular case presented in section II in which the sag has low imbalance (i.e. $\max \left\{V_{a}, V_{b}, V_{c}\right\}-\min \left\{V_{a}, V_{b}, V_{c}\right\}<$ $\overline{\mathcal{V}}-\underline{\mathcal{V}}$ ), the limits in (32) and (33) need to be modified to acomplish the aforementioned objective as

$$
\begin{aligned}
& \max \left\{V_{a}^{*}, V_{b}^{*}, V_{c}^{*}\right\}=\underline{\mathcal{V}}+\max \left\{V_{a}, V_{b}, V_{c}\right\}-\min \left\{V_{a}, V_{b}, V_{c}\right\} \\
& \min \left\{V_{a}^{*}, V_{b}^{*}, V_{c}^{*}\right\}=\underline{\mathcal{V}}
\end{aligned}
$$

\section{Reactive Power References}

Once the desired targets for positive and negative sequence voltage have been established, the formulation for the reactive power references can be easily obtained. The proposed voltage support control to comply with the voltage limits is obtained by rearranging (19)-(22) with the target values

$$
\begin{aligned}
Q^{+} & =\frac{3}{2} \frac{\left(V^{+}\right)^{*}\left[\left(V^{+}\right)^{*}-V_{g}^{+}\right]}{\omega L_{g}} \\
Q^{-} & =\frac{3}{2} \frac{\left(V^{-}\right)^{*}\left[V_{g}^{-}-\left(V^{-}\right)^{*}\right]}{\omega L_{g}} .
\end{aligned}
$$

By injecting these amounts of positive and negative sequence reactive power, the positive and negative sequence voltage targets will be achieved. These targets have been computed to keep the maximum and minimum phase voltages within the safety region.
The step by step procedure of this reactive power control is shown in Fig. 5, from the detection of the sag to the synthesis of the power references and the current reference generator. Once the sag has been detected and the symmetric sequences obtained, it should be characterized and identified. Then, to implement the proposed control, $V_{g}^{+}$and $V_{g}^{-}$need to be computed based on previous power references $Q^{+}$and $Q^{-}$ and PCC measurements $V^{+}$and $V^{-}$according to (19) and (20). Then the targets $\left(V^{+}\right)^{*}$ and $\left(V^{-}\right)^{*}$ are obtained based on the desired safety values $\overline{\mathcal{V}}$ and $\underline{\mathcal{V}}$ for a given sequence angle $\varphi$ by applying (32)-(36). The new positive and negative reactive power references are derived from (38) and (39). Due to the dynamic behaviour of sequence extractors, the settling time in perturbed situations last one grid cycle approximately [42]. For this reason, the power reference block is triggered once per grid cycle to compute the new values of $Q^{+}$and $Q^{-}$, which remain constant in the flow diagram until the new update. Once the reactive power references are obtained, a current saturation strategy ensures that the injected currents will be safely limited to the maximum rated current of the inverter $I_{\max }$. The procedure to saturate the current injection is developed in the next section.

\section{Current Saturation}

This section is intended for the case of stiff grids where the voltage limits strategy proposed in (3) could not be achieved. Voltage support in stiff grids require higher reactive currents. Thus, the required reactive currents can overpass the safety limits of the inverter. To overcome this issue, a current saturation strategy is developed. To achieve this objective, the injected currents are mathematically derived and a correction factor is included to limit the maximum injected current to the safety limit $I_{\max }$.

Similarly to (23)-(25), the amplitude of the phase currents are

$$
\begin{aligned}
I_{a} & =\sqrt{\left(I^{+}\right)^{2}+\left(I^{-}\right)^{2}+2 I^{+} I^{-} \cos \left(\varphi_{I}\right)} \\
I_{b} & =\sqrt{\left(I^{+}\right)^{2}+\left(I^{-}\right)^{2}+2 I^{+} I^{-} \cos \left(\varphi_{I}-2 \pi / 3\right)} \\
I_{c} & =\sqrt{\left(I^{+}\right)^{2}+\left(I^{-}\right)^{2}+2 I^{+} I^{-} \cos \left(\varphi_{I}+2 \pi / 3\right)}
\end{aligned}
$$

where $\varphi_{I}=\pi-\varphi$. Note that from (40)-(42), the maximum phase current can be identified since the reactive power references and the voltage sequences are all known.

Once the theoretical injected currents are characterized, the limitation process can be started. If the required power references from (38) and (39) induce a current higher than the maximum allowable current of the inverter $\max \left\{I_{a}, I_{b}, I_{c}\right\}>$ $I_{\max }$, then these references should be modified in order to protect the inverter from overcurrents. A method for doing so is to modify the power references as

$$
\begin{aligned}
& Q_{\text {sat }}^{+}=Q^{+} \frac{I_{\max }}{\max \left\{I_{a}, I_{b}, I_{c}\right\}} \\
& Q_{\text {sat }}^{-}=Q^{-} \frac{I_{\max }}{\max \left\{I_{a}, I_{b}, I_{c}\right\}}
\end{aligned}
$$

and the effective value for positive sequence reactive power in the reference generator (15) and (16) should be 
TABLE I

SYSTEM PARAMETERS

\begin{tabular}{lccc}
\hline \hline & Symbol & Nominal value & per unit value \\
\hline base power & $S_{\text {base }}$ & $2 \mathrm{kVA}$ & 1.0 \\
base voltage & $V_{\text {base }}$ & $110 \mathrm{~V}(1-\mathrm{n}, \mathrm{rms}), 60 \mathrm{~Hz}$ & 1.0 \\
base current & $I_{\text {base }}$ & $6 \mathrm{~A}(\mathrm{rms})$ & 1.0 \\
active power production & $P$ & $750 \mathrm{~W}$ & 0.37 \\
grid inductor & $L_{g}$ & $5 \mathrm{mH}$ & 0.10 \\
dc-link voltage & $v_{d c}$ & $350 \mathrm{~V}$ & - \\
switching frequency & $f_{s}$ & $10 \mathrm{kHz}$ & - \\
\hline
\end{tabular}

selected as $\min \left\{Q^{+}, Q_{\text {sat }}^{+}\right\}$, and for the negative sequence as $\min \left\{Q^{-}, Q_{\text {sat }}^{-}\right\}$

It is worth mentioning that if the current saturation strategy is activated, then the resulting reactive power is lower than necessary to meet (3). In this case, even if the voltage support targets expressed in (32) and (33) cannot be accomplished, the overcurrent is properly controlled.

\section{EXPERIMENTAL RESULTS}

Based on the scheme of Fig. 2, a low rated power test platform has been built using an Amrel SPS-800-12 DC Power Source, a 2 kVA Semikron three-phase IGBT bridge, a Pacific Power AMX AC grid emulator and an inductance $L_{g}$ between the PCC and the grid. The nominal values of the system parameters are collected in Table I. The control algorithm is implemented on a Texas Instruments floatingpoint TMS320F28335 Digital Signal Processor. Before and after the sag, $750 \mathrm{~W}$ of active power feed the grid; this operating point corresponds to an arbitrary wind or solar power production (0.37 p.u.). During the fault, the proposed voltage support control is activated. The sequence extractor presented in [41] has been employed to obtain symmetric sequences at run-time. For the current loop, a proportional-resonant current controller has been used.

Based on [12], three tests have been programmed in order to show the dynamic behavior of the proposed reactive power control:

- test 1 is a single-phase-to-ground (type II) voltage sag,

- test 2 is a balanced three-phase (type III) voltage sag,

- test 3 is a phase-to-phase (type I) sag with slow recovery.

\section{A. Test 1}

Test 1 is an unbalanced single-phase-to-ground voltage sag which could be caused by a short circuit or lightning somewhere in the transmission or distribution network. The sag is time-varying to mimic real behavior of grid faults.

The PCC voltage waveforms and rms values without voltage support are presented in Fig. 6(a) and 6(b). These figures show the dynamic evolution of the voltage sag when no reactive power is injected. The next two figures, 7(a) and 7(b), illustrate the measurements when the proposed voltage support control is activated. As can be shown, the voltage at the PCC is regulated to the selected voltage limits $\overline{\mathcal{V}}=1.10$ p.u., $\underline{\mathcal{V}}=0.85$ p.u. which is the main objective of the proposed reactive power control.

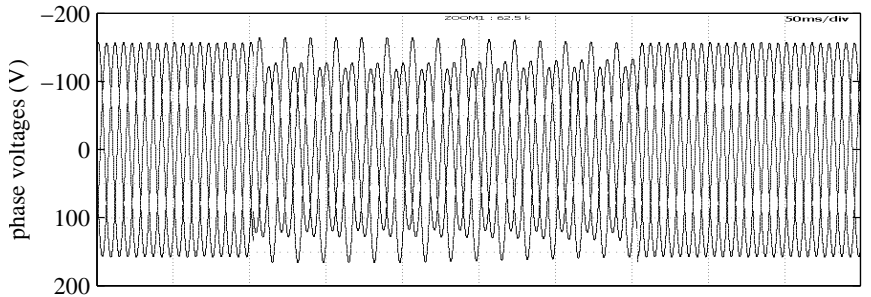

(a) Voltage waveforms $(50 \mathrm{~ms} / \mathrm{div})$.

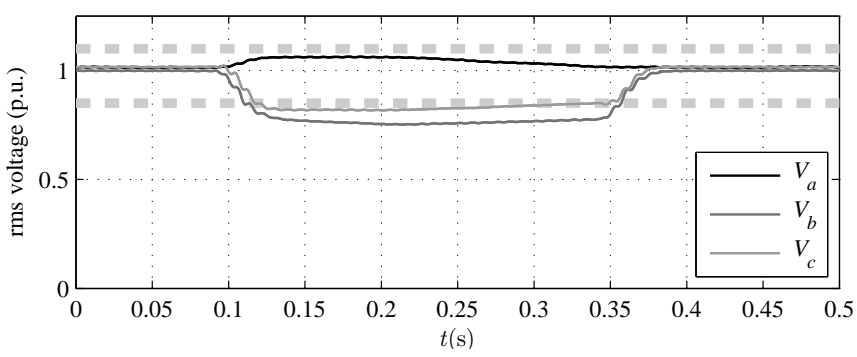

(b) Rms voltage.

Fig. 6. Test1: voltages without voltage support control.

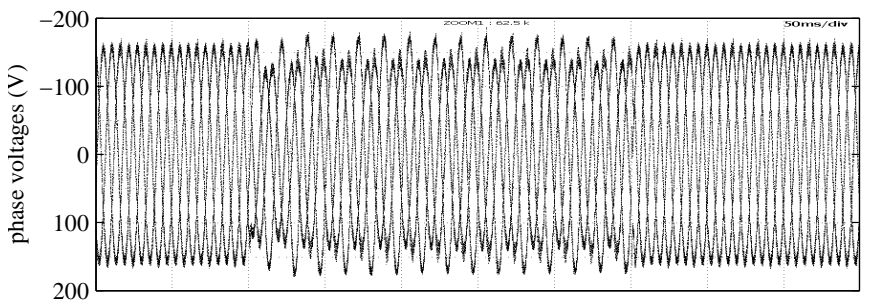

(a) Voltage waveforms $(50 \mathrm{~ms} / \mathrm{div})$.

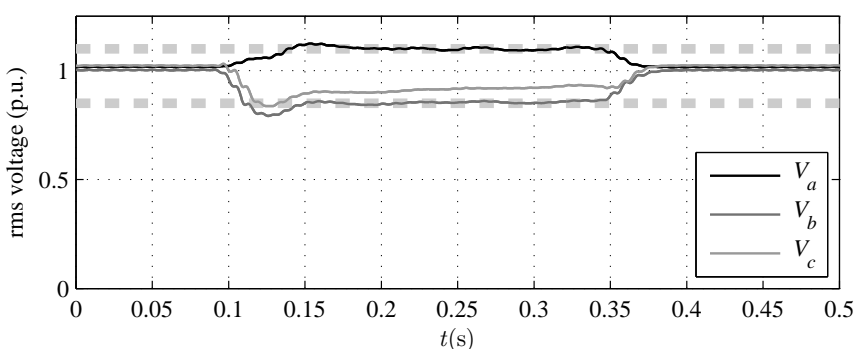

(b) Rms voltage.

Fig. 7. Test1: voltages with voltage support control.

The waveforms of the injected currents are presented in Fig. 8. Note that before and after the sag, the inverter injects balanced active currents, the current amplitudes in this situation are around 0.37 p.u. However, during the sag, the currents increase up to 0.9 p.u. It is worth mentioning that deeper voltage sags or smaller grid inductances will require higher reactive currents to regulate the phase voltages. Also, it should be pointed out that during the sag, there exists an inherent current imbalance due to the injection of both positive and negative sequence reactive currents.

Fig. 9 clearly shows the proposed solution to the stated problem. This figure presents the positive and negative reactive power references. These references are computed on-line according to the flow diagram in section V-C. Fig. 9 also shows the instantaneous reactive power $q$, plotted in the thinner line. As expected, a significant oscillation at twice the grid frequency can be observed during the sag due to the imbalance in the system. 


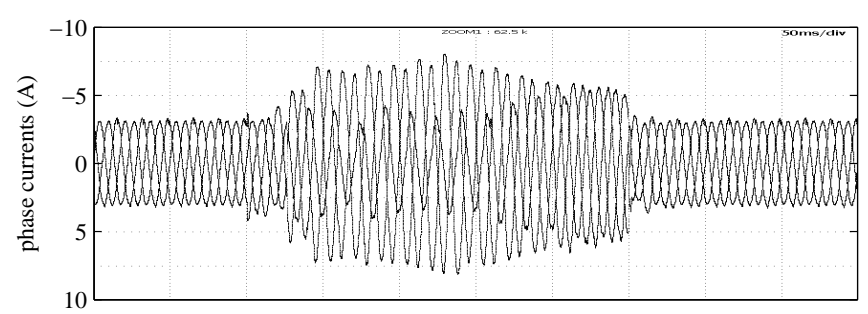

Fig. 8. Test 1: inverter current waveforms $(50 \mathrm{~ms} / \mathrm{div})$.

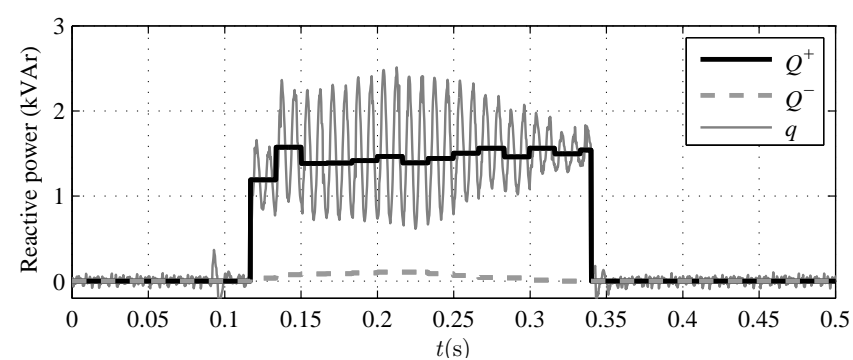

Fig. 9. Test 1: Positive and negative reactive power references, and instantaneous total reactive power.

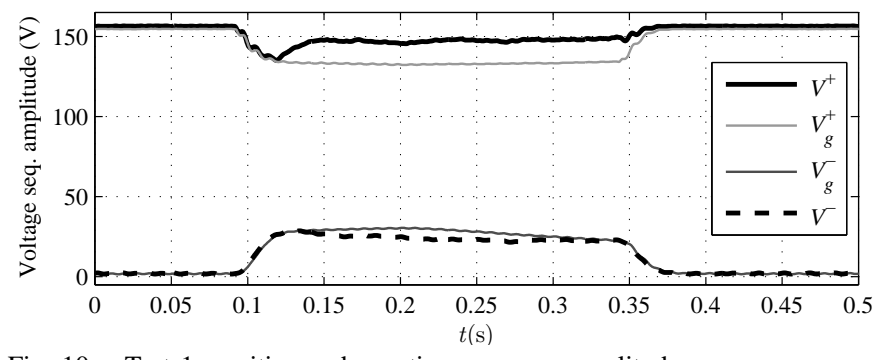

Fig. 10. Test 1: positive and negative sequence amplitude.

Fig. 10 shows the measured positive voltage sequence $V^{+}$ and the calculated positive sequence grid voltage $V_{g}^{+}$when the voltage support strategy is implemented. The negative grid sequence $V_{g}^{-}$and the PCC measure $V^{-}$are shown below in the graph. As desired, to raise the voltage in all the phases, the PCC positive sequence voltage should be increased. On the other hand, the negative sequence voltage is decreased, which helps to equalize the phase voltages.

\section{B. Test 2}

Test 2 presents a balanced three-phase voltage sag caused by a motor starting with high inrush current. Balanced voltage sags have no negative sequence voltage, therefore the control strategy should inject positive sequence reactive power until the minimum safety voltage $\underline{\mathcal{V}}$ is achieved in the three phases.

The rms voltages without voltage support are shown in Fig. 11. The effect of the voltage support control at the PCC can be appreciated in Fig. 12. With this strategy, the PCC voltages are within the safety region, which is the main objective of the proposed control scheme.

In Fig. 13, positive and negative reactive power references are shown. As stated above, only positive sequence reactive power is injected during the sag. Therefore, the negative sequence reactive power reference is set to zero. The instantaneous total reactive power is represented by the thinner line. Note that the instantaneous reactive power follows the reference and that no oscillations at twice the grid frequency

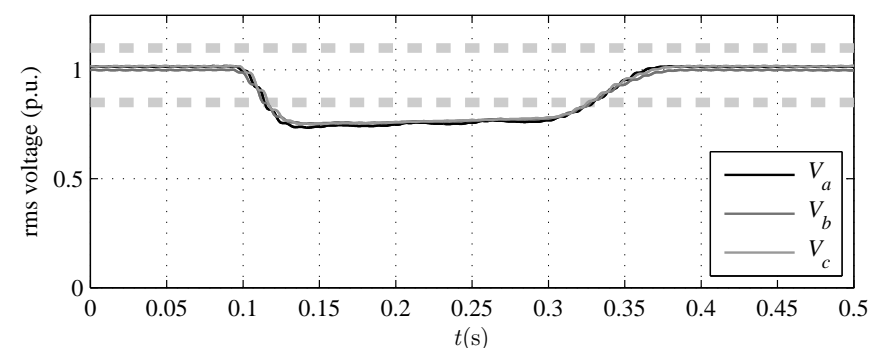

Fig. 11. Test 2: rms voltages without voltage support.

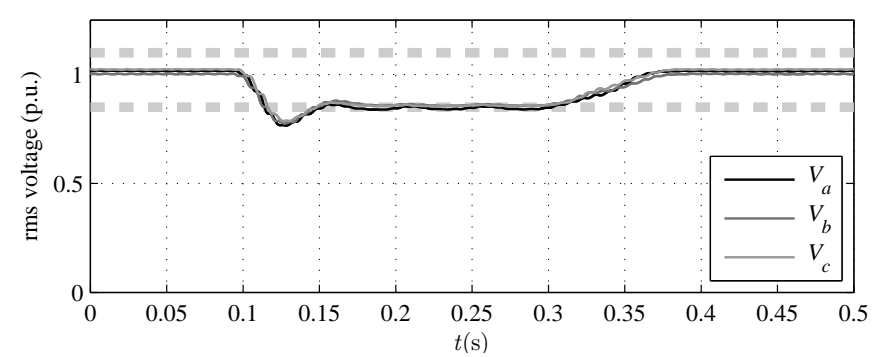

Fig. 12. Test 2: rms voltages with voltage support.

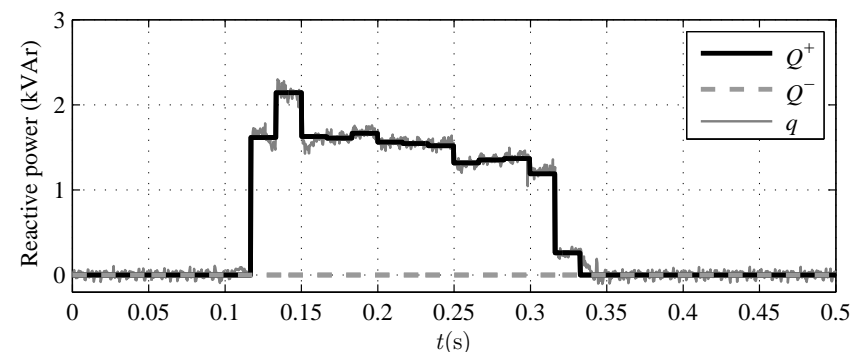

Fig. 13. Test 2: Positive and negative reactive power references, and instantaneous total reactive power.

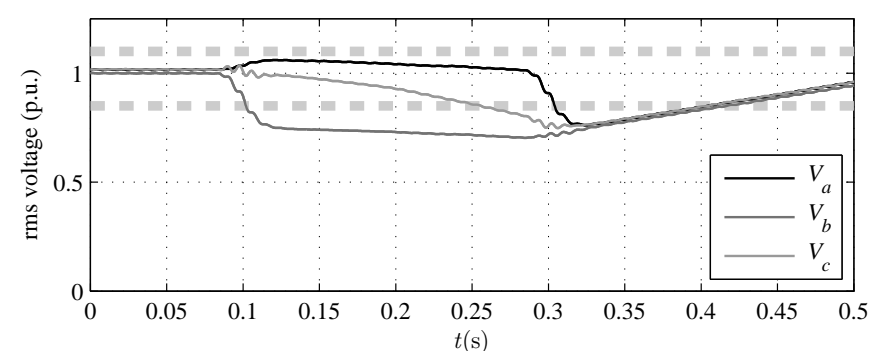

Fig. 14. Test 3: rms voltages without voltage support.

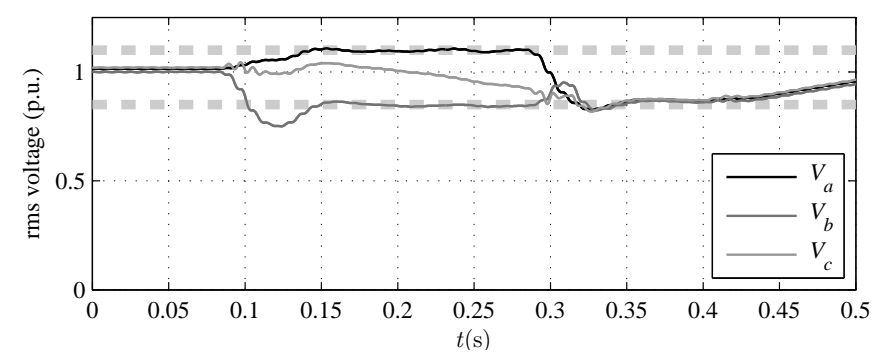

Fig. 15. Test 3: rms voltages with voltage support.

are present because no imbalance exists in this type of voltage sag.

\section{Test 3}

Test 3 is a voltage sag with slow recovery. Fig. 14 presents the rms voltages without voltage support. The sag begins as a type I $(t=0.1 \mathrm{~s})$, evolving to a type II $(t=0.3 \mathrm{~s})$, then the 
sag is cleared and the system suffers a slow voltage recovery as a type III $(t>0.3 \mathrm{~s})$.

The rms voltages at the PCC when the voltage support is activated are shown in Fig. 15. The results show that the reactive power control is able to keep the voltages within the safety limits, which corroborates that the proposed control strategy can comply with the voltage requirements even in complex situations.

\section{CONCLUSIONS}

This paper presents a reactive power control scheme for three-phase grid-connected inverters operating under voltage sags. The control objective is to regulate the maximum and minimum phase voltages within the limits established in grid codes for continuous operation. Therefore, DG power plants can avoid disconnection while helping to mitigate the adverse effects of grid faults.

The problem can be divided into two aspects: i) setting the positive and negative sequence targets based on the desired phase voltages, and ii) setting the positive and negative reactive power references based on an equivalent impedance grid model. The control scheme solves these two issues and presents a step by step realization of the proposal.

The proposed reactive power control shows good dynamic behavior as can be seen from the experimental results. The control proposal is able to set the voltage references in any type of balanced or unbalanced voltage sag. Moreover, the set of experiments prove that the control proposal can even support time-varying grid faults.

Future work will focus on the behavior of the control scheme in more complex networks, and the selection of different control objectives to improve the overall system performance. In addition, the constraints and communication requirements for a proper power plant design should be analyzed.

\section{REFERENCES}

[1] F. Blaabjerg, R. Teodorescu, M. Liserre, and A. Timbus, "Overview of control and grid synchronization for distributed power generation systems," IEEE Trans. Ind. Electron., vol. 53, no. 5, pp. 1398-1409, Oct. 2006.

[2] J. Rocabert, A. Luna, F. Blaabjerg, and P. Rodriguez, "Control of power converters in ac microgrids," IEEE Trans. on Power Electron., vol. 27, no. 11 , pp. 4734-4749, 2012.

[3] S.-F. Chou, C.-T. Lee, H.-C. Ko, and P.-T. Cheng, "A low-voltage ride-through method with transformer flux compensation capability of renewable power grid-side converters," IEEE Trans. Power Electron., vol. 29, no. 4, pp. 1710-1719, 2014.

[4] V. Ignatova, P. Granjon, S. Bacha, and F. Dumas, "Classification and characterization of three phase voltage dips by space vector methodology," in Int. Conf. on Future Power Systems, Nov. 2005.

[5] B. Kirby and E. Hirst, "Ancillary-service details: Voltage control," ORNL/CON-453, Oak Ridge National Laboratory, Oak Ridge TN, Rep. Dec., 1997.

[6] Offprint of the Operation Procedure O.P. 12.2: Technical requirements for wind power and photovoltaic installations and any generating facilities whose technology does not consist on a synchronous generator directly connected to the grid., Asociación Empresarial Eólica, Oct. 2008, [Online]. Available: www.aeeolica.org.

[7] J. Martinez and P. Kjaer, "Fast voltage control in wind power plants," in IEEE Power and Energy Society General Meeting, Jul. 2011, pp. 1 -7 .
[8] J. A. Diaz de Leon, B. Kehrli, and A. Zalay, "How the Lake Bonney wind farm met ESCOSA's, NEMMCO's and ElectraNet's rigorous interconnecting requirements," in IEEE Power and Energy Society General Meeting, 2008, pp. 1 -7.

[9] S. Martin-Martinez, E. Gomez-Lazaro, A. Molina-Garcia, A. ViguerasRodriguez, M. Milligan, and E. Muljadi, "Participation of wind power plants in the spanish power system during events," in 2012 IEEE Power and Energy Society General Meeting, 2012, pp. 1-8.

[10] F. Blaabjerg, M. Liserre, and K. Ma, "Power electronics converters for wind turbine systems," IEEE Trans. Ind. Appl., vol. 48, no. 2, pp. 708 -719 , Mar. 2012.

[11] M. Altin, O. Goksu, R. Teodorescu, P. Rodriguez, B.-B. Jensen, and L. Helle, "Overview of recent grid codes for wind power integration," in 12th Int. Conf. on Optimization of Electrical and Electronic Equipment, May 2010, pp. 1152-1160.

[12] M. Bollen, M. Stephens, S. Djokic, K. Stockman, B. Brumsickle, J. Milanovic, J. R. Gordn, R. Neumann, G. Ethier, F. Corcoles, A. Ferguson, P. Goossens, P. Ligot, A. Lopes Leiria, P. Marteyn, A. McEachern, J. Mentzer, I. McMichael, U. Minnaar, K. van Reusel, and F. Zavoda, "Voltage dip immunity of equipment and installations," CIGRE/CIRED/UIE Joint Working Group C4.110, pp. 1-279, Apr. 2010.

[13] A. Camacho, M. Castilla, J. Miret, J. Vasquez, and E. Alarcón-Gallo, "Flexible voltage support control for three phase distributed generation inverters under grid fault," IEEE Trans. Ind. Electron., vol. 60, no. 4, pp. 1429-1441, 2013.

[14] X. Guo, X. Zhang, B. Wang, W. Wu, and J. Guerrero, "Asymmetrical grid fault ride-through strategy of three-phase grid-connected inverter considering network impedance impact in low voltage grid," IEEE Trans. Power Electron., In press.

[15] A. Vidal, F. Freijedo, A. Yepes, P. Fernandez-Comesana, J. Malvar, O. Lopez, and J. Doval-Gandoy, "Assessment and optimization of the transient response of proportional-resonant current controllers for distributed power generation systems," IEEE Trans. Ind. Electron., vol. 60, no. 4, pp. 1367-1383, 2013.

[16] J. Yao, H. Li, Z. Chen, X. Xia, and X. Chen, "Enhanced control of a DFIG-based wind-power generation system with series grid-side converter under unbalanced grid voltage conditions," IEEE Trans. Power Electron., vol. 28, no. 7, pp. 3167-3181, Jul. 2013.

[17] S. Alepuz, S. Busquets-Monge, J. Bordonau, J. Martinez-Velasco, C. Silva, J. Pont, and J. Rodriguez, "Control strategies based on symmetrical components for grid-connected converters under voltage dips," IEEE Trans. Ind. Electron., vol. 56, no. 6, pp. 2162-2173, Jun. 2009.

[18] M. Castilla, J. Miret, J. Sosa, J. Matas, and L. García de Vicuna, "Grid-fault control scheme for three-phase photovoltaic inverters with adjustable power quality characteristics," IEEE Trans. Power Electron. vol. 25, no. 12, pp. 2930-2940, Dec. 2010.

[19] F. Wang, J. L. Duarte, and M. A. M. Hendrix, "Pliant active and reactive power control for grid-interactive converters under unbalanced voltage dips," IEEE Trans. Power Electron., vol. 26, no. 5, pp. 1511-1521, May 2011.

[20] M. Reyes, P. Rodriguez, S. Vazquez, A. Luna, R. Teodorescu, and J. Carrasco, "Enhanced decoupled double synchronous reference frame current controller for unbalanced grid-voltage conditions," IEEE Trans. Power Electron., vol. 27, no. 9, pp. 3934 -3943, Sep. 2012.

[21] C. Liu, D. Xu, N. Zhu, F. Blaabjerg, and M. Chen, "Dc-voltage fluctuation elimination through a dc-capacitor current control for DFIG converters under unbalanced grid voltage conditions," IEEE Trans. Power Electron., vol. 28, no. 7, pp. 3206-3218, Jul. 2013.

[22] P. Rodriguez, G. Medeiros, A. Luna, M. Cavalcanti, and R. Teodorescu, "Safe current injection strategies for a statcom under asymmetrical grid faults," in IEEE Energy Conversion Congr. and Expo. (ECCE), Sep. 2010, pp. $3929-3935$.

[23] P. Rodriguez, A. Luna, J. Hermoso, I. Etxeberria-Otadui, R. Teodorescu, and F. Blaabjerg, "Current control method for distributed generation power generation plants under grid fault conditions," in 37th Ann. Conf. on IEEE Ind. Electron. Society (IECON), Nov. 2011, pp. $1262-1269$.

[24] Y. Mohamed and E. El-Saadany, "A control scheme for PWM voltagesource distributed-generation inverters for fast load-voltage regulation and effective mitigation of unbalanced voltage disturbances," IEEE Trans. Ind. Electron., vol. 55, no. 5, pp. 2072 -2084, May 2008.

[25] H.-S. Song and K. Nam, "Dual current control scheme for PWM converter under unbalanced input voltage conditions," IEEE Trans. Ind. Electron., vol. 46, no. 5, pp. 953 -959, Oct. 1999.

[26] M. Castilla, J. Miret, A. Camacho, J. Matas, E. Alarcón-Gallo, and L. García de Vicuna, "Coordinated reactive power control for static 
synchronous compensators under unbalanced voltage sags," in IEEE Int. Symp. on Industrial Electronics (ISIE), May 2012, pp. 987 -992.

[27] M. Castilla, J. Miret, A. Camacho, J. Matas, and L. de Vicuna, "Voltage support control strategies for static synchronous compensators under unbalanced voltage sags," IEEE Trans. Ind. Electron., In press.

[28] T. Lee, S. Hu, and Y. Chan, "D-STATCOM with positive-sequence admittance and negative-sequence conductance to mitigate voltage fluctuations in high-level penetration of distributed generation systems," IEEE Trans. Ind. Electron., vol. 60, no. 4, pp. 1417-1428, Apr. 2013.

[29] S. Chaudhary, R. Teodorescu, P. Rodriguez, P. Kjaer, and A. Gole, "Negative sequence current control in wind power plants with VSCHVDC connection," IEEE Trans. Sustainable Energy, vol. 3, no. 3, pp. $535-544$, Jul. 2012.

[30] "Resolution-P.O.12.3-Response requirements against voltage dips in wind installations," Red Electrica (REE), Operat. Proced., Oct. 2006.

[31] J. Miret, A. Camacho, M. Castilla, L. García de Vicuna, and J. Matas, "Control scheme with voltage support capability for distributed generation inverters under voltage sags," IEEE Trans. Power Electron., vol. 28, no. 11, pp. 5252-5262, Nov. 2013.

[32] J. Mora, J. Melndez, D. Llanos, J. Colomer, and X. Snchez J., Corbella, "Classification of sags measured in a distribution substation using a fuzzy tool," in ICREPQ Int. Conf. on Renewable Energy and Power Quality, 2003, pp. 1-7.

[33] Procedimiento de operación 7.4: Servicio complementario de control de tensión de la red de transporte, Red Eléctrica de España, Oct. 2000, [Online]. Available: www.ree.es.

[34] "IEEE standard definitions for the measurement of electric power quantities under sinusoidal, nonsinusoidal, balanced, or unbalanced conditions," IEEE Std 1459-2010, pp. 1-40, Mar. 2010.

[35] L. Asiminoaei, R. Teodorescu, F. Blaabjerg, and U. Borup, "Implementation and test of an online embedded grid impedance estimation technique for PV inverters," IEEE Trans. Ind. Electron., vol. 52, no. 4, pp. 1136 - 1144, Aug. 2005.

[36] A. Moallem, D. Yazdani, A. Bakhshai, and P. Jain, "Frequency domain identification of the utility grid parameters for distributed power generation systems," in 26th Ann. IEEE Applied Power Electronics Conf. and Expo. (APEC), Mar. 2011, pp. $965-969$.

[37] A. Timbus, R. Teodorescu, and P. Rodriguez, "Grid impedance identification based on active power variations and grid voltage control," in 42nd Ann. Meeting. Conf. Record of the 2007 IEEE Industry Applications Conference (IAS), Sep. 2007, pp. 949 -954.

[38] S. Cobreces, E. Bueno, D. Pizarro, F. Rodriguez, and F. Huerta, "Grid impedance monitoring system for distributed power generation electronic interfaces," IEEE Trans. Instrum. Meas., vol. 58, no. 9, pp. $3112-3121$, Sep. 2009.

[39] N. Hoffmann and F. W. Fuchs, "Minimal invasive equivalent grid impedance estimation in inductive-resistive power-networks using extended kalman-filter," IEEE Trans. Power Electron., In press.

[40] K. Ma and F. Blaabjerg, "Thermal optimised modulation methods of three-level neutral-point-clamped inverter for $10 \mathrm{MW}$ wind turbines under low-voltage ride through," IET Power Electron., vol. 5, no. 6, pp. 920 -927, Jul. 2012.

[41] F. Rodriguez, E. Bueno, M. Aredes, L. Rolim, F. Neves, and M. Cavalcanti, "Discrete-time implementation of second order generalized integrators for grid converters," in 34th Аnпи. Conf. of IEEE Ind. Electron., Nov. 2008, pp. 176-181.

[42] J. Matas, M. Castilla, J. Miret, L. Garcia de Vicuna, and R. Guzman, "An adaptive prefiltering method to improve the speed/accuracy tradeoff of voltage sequence detection methods under adverse grid conditions," IEEE Trans. Ind. Electron., vol. 61, no. 5, pp. 2139-2151, 2014.

[43] F. Neves, H. Souza, E. Bueno, M. Rizo, F. Bradaschia, and M. Cavalcanti, "A space-vector discrete fourier transform for detecting harmonic sequence components of three-phase signals," in 35th Аnпи. Conf. of IEEE Ind. Electron., Nov. 2009, pp. 3631-3636.

[44] P. Rodriguez, A. Luna, R. Muñoz Aguilar, I. Etxeberria-Otadui, R. Teodorescu, and F. Blaabjerg, "A stationary reference frame grid synchronization system for three-phase grid-connected power converters under adverse grid conditions," IEEE Trans. Power Electron., vol. 27, no. 1, pp. 99-112, 2012.

[45] P. Rodriguez, A. Luna, I. Candela, R. Mujal, R. Teodorescu, and F. Blaabjerg, "Multiresonant frequency-locked loop for grid synchronization of power converters under distorted grid conditions," IEEE Trans. Ind. Electron., vol. 58, no. 1, pp. 127-138, Jan. 2011.

[46] P. Roncero-Sánchez, X. del Toro García, A. Parreno Torres, and V. Feliu, "Fundamental positive- and negative-sequence estimator for grid synchronization under highly disturbed operating conditions," IEEE Trans. Power Electron., vol. 28, no. 8, pp. 3733-3746, Aug. 2013.

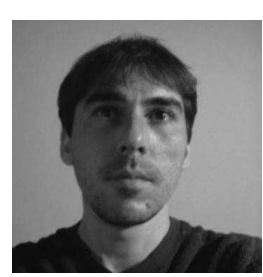

Antonio Camacho received the B.S. degree in chemical engineering in 2000 and the M.S. degree in automation and industrial electronics in 2009, both from the Technical University of Catalonia, Barcelona, Spain. Currently, he is pursuing the Ph.D. degree in electronic engineering also at the Technical University of Catalonia. His research interests include networked and embedded control systems, industrial informatics, and power electronics.

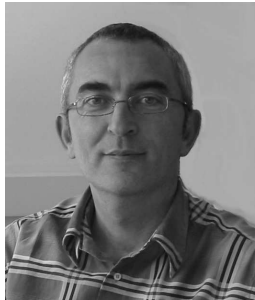

Miguel Castilla received the B.S., M.S. and Ph.D. degrees in telecommunication engineering from the Technical University of Catalonia, Barcelona, Spain, in 1988, 1995, and 1998, respectively.

Since 2002, he has been an Associate Professor in the Department of Electronic Engineering, Technical University of Catalonia, where he teaches courses on analog circuits and power electronics. His research interests are in the areas of power electronics, nonlinear control, and renewable energy systems.

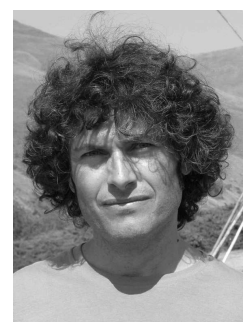

Jaume Miret (M01) received the B.S. degree in telecommunications and the M.S. and Ph.D. degrees in electronics from the Technical University of Catalonia, Barcelona, Spain, in 1992, 1999, and 2005, respectively.

$\mathrm{He}$ is currently an Associate Professor with the Department of Electronic Engineering, Technical University of Catalonia, Vilanova i la Geltrú, Spain, where he teaches courses on digital design and circuit theory. His research interests include dc-ac converters, active power filters, and digital control.

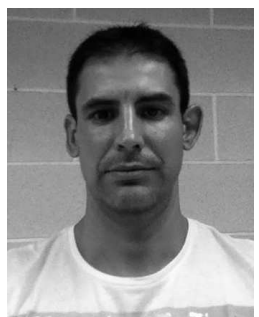

Ramon Guzman received the B.S. and M.S. degrees in telecomunications engineering from the Technical University of Catalonia, Barcelona, Spain in 1999 and 2004, respectively. $\mathrm{He}$ is currently working toward the Ph.D. degree in the Power and Control Electronics Systems (SEPIC) group.

Since 2001, he is an Associate Professor of the Comunications and Signal Theory Department at the Technical University of Catalonia, Barcelona, Spain. His current research interests are in the area of nonlinear and adaptive control for three phase power

converters

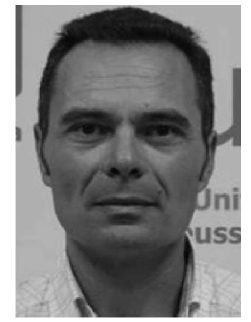

Angel Borrell received the B.S. degree in electrical engineering, M.S. degree in automation and industrial electronics engineering and $\mathrm{PhD}$ in electronics engineering from the Technical University of Catalonia, Barcelona, Spain, in 1993, 2006 and 2012 respectively.

Since 1994, he has been an Associate Professor in the Department of Electrical Engineering, Escola Universitària Salesiana de Sarrià, where he teaches courses on electrical machines and automation. His research interest are in the areas of power electronics, electric motor drives and renewable energy systems. 